\title{
Intact Visual Perceptual Discrimination in Humans in the Absence of Perirhinal Cortex
}

\author{
Craig E.L. Stark ${ }^{2}$ and Larry R. Squire ${ }^{1,3}$ \\ ${ }^{1}$ Veterans Affairs Medical Center, San Diego, California 92161, USA \\ ${ }^{2}$ University of California San Diego, La Jolla, California 92093, USA
}

\begin{abstract}
While the role of the perirhinal cortex in declarative memory has been well established, it has been unclear whether the perirhinal cortex might serve an additional nonmnemonic role in visual perception. Evidence that the perirhinal cortex might be important for visual perception comes from a recent report that monkeys with perirhinal cortical lesions are impaired on difficult (but not on simple) visual discrimination tasks. We administered these same tasks to nine amnesic patients, including three severely impaired patients with complete damage to perirhinal cortex bilaterally (E.P., G.P., and G.T.). The patients performed all tasks as well as controls. We suggest that the function of perirhinal cortex as well as antero-lateral temporal cortex may differ between humans and monkeys.
\end{abstract}

Declarative memory requires the integrity of the hippocampal region and the adjacent parahippocampal, entorhinal, and perirhinal cortices. Together, these structures constitute the medial temporal lobe memory system (Milner et al. 1998). Recently, interest has focused on the function of the perirhinal cortex (for review, see Suzuki 1996). The importance of the perirhinal cortex for declarative memory has been well established (see Mishkin and Murray 1994; for review, see Squire and Zola 1997). However, as $64 \%$ of the cortical input to perirhinal cortex originates in visual areas, including areas TE and TEO (Suzuki and Amaral 1994), it is plausible that the perirhinal cortex might also serve an additional (nonmnemonic) role in visual perception.

In the monkey, lesions of the perirhinal cortex have been shown to impair performance on a test of delayed (but not immediate) recognition memory (Buffalo et al. 1999). In contrast, lesions of the adjacent area TE impaired performance on both the immediate and delayed test. In addition, amnesic patients with large medial temporal lobe lesions that included the perirhinal cortex (patients E.P. and G.T.) were impaired on delayed (but not immediate) recognition memory for complex-patterned colored stimuli (Buffalo et al. 1998). These findings of intact performance at short delays have suggested that the perirhinal cortex does not contribute to visual perception.

Evidence that the perirhinal cortex might play a role in visual perception has come from reports of impaired performance on visual perceptual tasks following perirhinal cortex lesions in monkeys (Eacott et al. 1994; Buckley and Gaffan 1997, 1998a,b). However, incidental damage to area

${ }^{3}$ Corresponding author.

E-MAIL 1squire@ucsd.edu; FAX (858) 552-7457.

Article and publication are at www.learnmem.org/cgi/doi/10.1101/ $\operatorname{lm} .35000$.
TE may account for some of these observations (for additional discussion, see Buffalo et al. 1999). More recent evidence comes from reports that monkeys with perirhinal lesions were impaired at performing difficult visual discrimination tasks (Buckley et al. 1998; Buckley and Gaffan, in press). For example, when monkeys with perirhinal cortical lesions saw five different views of the same three-dimensional object and another view of a different three-dimensional object-all views obscured by a white-noise maskthe monkeys were impaired at choosing which of the six pictures was of a different object. Similarly, when shown five different views of the same face (monkey or human) and another view of a different face, monkeys with perirhinal cortical lesions were impaired at choosing which of the six pictures was of a different face. When less difficult tasks were presented (e.g., color discrimination or object discrimination without a white-noise mask), monkeys with perirhinal cortical lesions performed normally. Thus, it appeared that impaired visual perception following perirhinal damage occurred on the most difficult tasks.

In this study, we administered seven of the same visual discrimination "oddball" tasks that had been administered to monkeys to three groups of amnesic patients. In each task, participants were shown six stimuli and asked to decide which of the six did not belong with the others. Three of the tasks (color, size, and polygon discrimination) were ones that monkeys with perirhinal cortex lesions performed normally (Buckley et al. 1998; Buckley and Gaffan, in press). Four of the tasks (one task of face discrimination and three tasks of object discrimination under noise) were ones that revealed an impairment in monkeys with perirhinal cortex lesions (Buckley et al. 1998; Buckley and Gaffan, in press). Three of these four tasks involved objects embedded in varying levels of masked noise or "snow" (30\%-80\%) to

LEARNING \& MEMORY 7:273-278 @ 2000 by Cold Spring Harbor Laboratory Press ISSN1072-0502/00 \$5.00

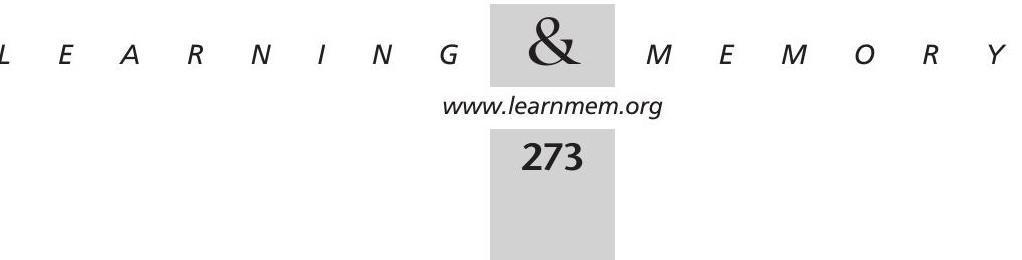


obscure the stimuli (Fig. 1a,b). The fourth task involved faces (Fig. 1c). Amnesic patients, including three encephal-
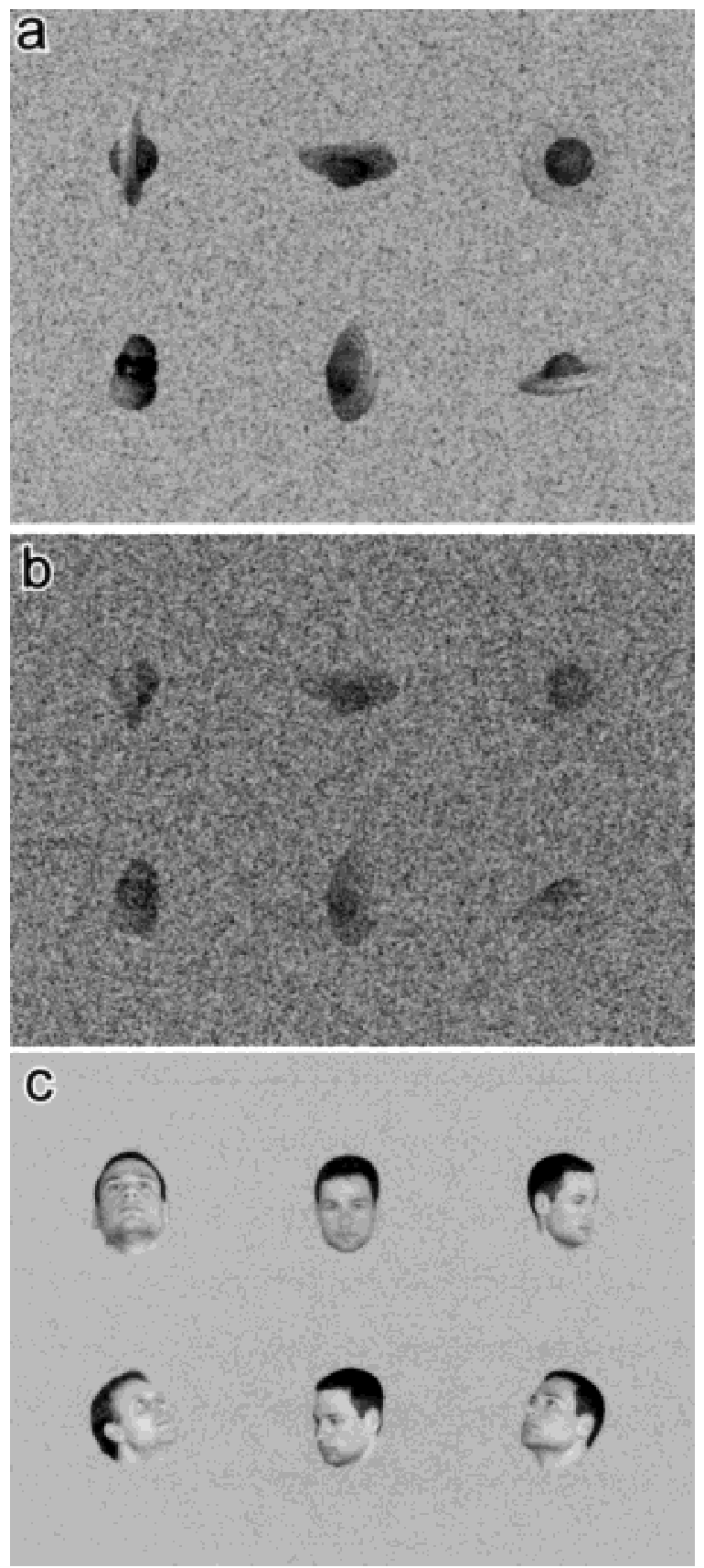

Figure 1 Examples of trials from three of the difficult tasks. (a) Visually degraded object discrimination with a $30 \%-40 \%$ whitenoise mask (Task 4). (b) Visually degraded object discrimination (the same trial) with a $70 \%-80 \%$ white-noise mask (Task 6). (c) Face discrimination (Task 7). Although performance on each of these tasks has been reported to be impaired in monkeys with perirhinal damage (Buckley et al. 1998; Buckley and Gaffan, in press), patients with complete damage to perirhinal cortex bilaterally performed normally. The correct choice in each of these examples is the lower left corner. litic patients with extensive damage to the medial temporal lobe (including the entire perirhinal cortex bilaterally, as shown in Fig. 2 ), were unimpaired on all of the tasks.

\section{RESULTS}

Across the three administrations of the seven tasks, controls (CON) scored $80.0 \%$ correct, patients with extensive damage to the medial temporal lobe due to encephalitis (ENC) scored $79.6 \%$ correct, patients with damage limited to the hippocampal formation $(\mathrm{H})$ scored $81.3 \%$ correct, and patients with damage due to Korsakoff's syndrome (KOR) scored $74.6 \%$ correct. Figure 3 shows the percentage correct scores separately for the three perceptual tasks that monkeys with perirhinal cortex damage could perform normally (color, size, and polygon discrimination) and for the four tasks that monkeys with perirhinal cortex damage performed poorly (three visually degraded object-discrimination tasks and face discrimination). The control group scored $90.2 \%$ correct on the first group of three tasks, and the encephalitic group scored $92.5 \%$ correct $(H=91.5 \%$, $\mathrm{KOR}=85.7 \%$ ). For the four visually degraded object-discrimination tasks and the face discrimination task, the control group scored $72.2 \%$ correct and the encephalitic group scored $70.0 \%$ correct $(H=73.8 \%, K O R=66.3 \%)$. None of the intergroup differences were significant for either group of tasks $(P s>0.3)$.

Figure 4 shows performance on each of the seven individual tasks. Independent-samples $t$-tests comparing performance of the controls to each of the amnesic groups revealed no impairment on any of the tasks (ENC, all $P$ s $>0.15 ; \mathrm{H}$, all $P$ s $>0.39 ;$ Kall $P$ s $>0.07)$. The only reliable difference observed was a $4.2 \%$ higher score on the sizediscrimination task for the amnesic patients with damage restricted to the hippocampal formation $(\mathrm{H})$ relative to the control group $(t(6)=4.0, P<.01)$. In addition, the patients with Korsakoff's syndrome were marginally poorer on the face discrimination task compared to the control group $[t(6)=2.2, P=0.074]$. Importantly, the encephalitic group performed as well as the controls on all the tasks.

All seven experiments were administered to each participant on three separate occasions. Across the three test sessions, there was a small improvement in performance from $76.8 \%$ correct to $80.5 \%$ correct overall. A repeated measures ANOVA found a main effect of test session $[F(2,20)=5.0, P<.05]$ and a significant linear contrast associated with test session $[F(1,10)=6.6, P<0.05]$. All four groups exhibited this improvement, and there was no interaction between test session and group $(P=0.44)$. An interaction between test session and task was also observed $[F(12,120)=516, P=0.001]$. The source of this interaction was attributable almost entirely to an improvement between the first and second tests on the most difficult visually degraded object-discrimination ("snow") task. Across all participants, performance on this task improved from $45 \%$

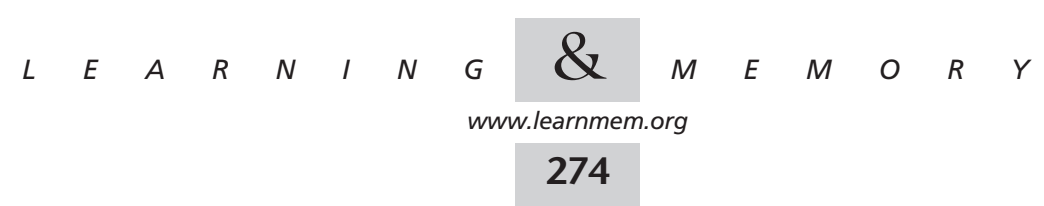



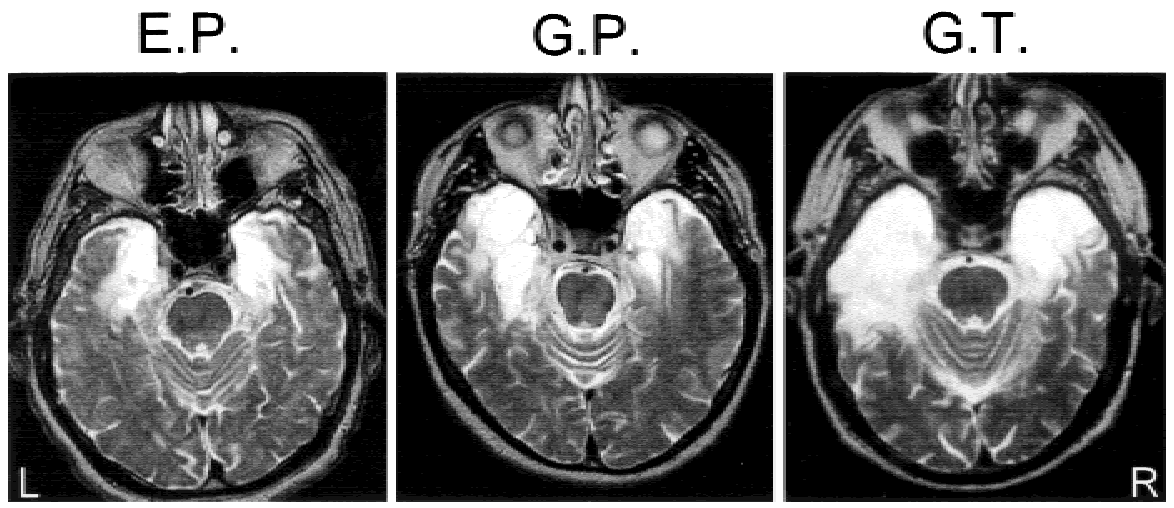

crimination under noise) were the more difficult tasks that had revealed impairment in monkeys with perirhinal cortex lesions (Buckley et al. 1998; Buckley and Gaffan, in press).

The patients performed all of the tasks as well as controls. Importantly, the three encephalitic patients performed normally on each of the seven tasks. Of note, they exhibited a modest improvement in the most difficult task (object discrimination with a $70 \%$ $80 \%$ white noise mask) across the three test sessions. However, similar practice effects were observed in all groups of participants.

The only evidence of impaired performance was a marginally significant reduction in accuracy in the face discrimination task by patients with Korsakoff's syndrome. Patients with Korsakoff's syndrome have been shown previously to be impaired in their ability to recognize or match faces that have had alterations to their surface features (e.g., direction of gaze, facial expression, or hair style) because these patients tend to encode each face based only on

correct to $68 \%$ correct between the first and second test session $[t(13)=5.3, P=0.001]$ and remained at $68 \%$ on the third test session. All four groups of participants exhibited similar increases in performance on this task (CON $=19.4 \%$, $\mathrm{ENC}=22.6 \%, \mathrm{H}=19.0 \%, \mathrm{KOR}=34.0 \%$ ). By contrast, performance did not significantly improve on the other tasks $($ Color $=-0.6 \%$, Polygon $=-0.7 \%$, Size $=-2.4 \%, 30 \%-40 \%$ Snow $=-3.1 \%, 50 \%-60 \%$ Snow $=2.7 \%$, Faces $=6.8 \%)$.

\section{DISCUSSION}

Seven visual discrimination tasks were administered to nine amnesic patients (three encephalitic patients with extensive medial temporal lobe damage including complete bilateral loss of the perirhinal cortex, three patients with damage limited to the hippocampal formation, and three patients with Korsakoff's syndrome) and five healthy control volunteers. Three of the tasks (color, size, and polygon discrimination) were ones on which monkeys with perirhinal cortex lesions have performed normally (Buckley et al. 1998; Buckley and Gaffan, in press). Four of the tasks (one task of face discrimination and three tasks of object dis- superficial features (Dricker et al. 1978; Biber et al. 1981). Given the high degree of similarity between the faces used in our test, relying only on superficial facial features would be likely to result in poor performance.

We considered three explanations for why the patients with perirhinal cortical damage performed well on tasks that monkeys with perirhinal cortical lesions performed poorly. First, the tasks on which the monkeys were impaired might have been more difficult for the monkeys than they were for the patients. This possibility is unlikely. Both the percent correct scores (e.g., average percentage correct in $70 \%-80 \%$ snow $=60.5 \%$ ) and the verbal reports from the participants suggested that several of the tasks were quite difficult. Second, it is possible that the monkeys with perirhinal cortical lesions had additional damage outside the perirhinal cortex. For example, damage to the laterally adjacent area TE is known to produce visual perceptual impairments (Gross 1973; Mishkin 1982; Miyashita 1993; Buffalo et al. 1999). Further, previous studies of monkeys with perirhinal cortical lesions did include damage to area TE that may have been sufficient to explain the observed impairments (Buffalo et al. 1999). Although descriptions of the

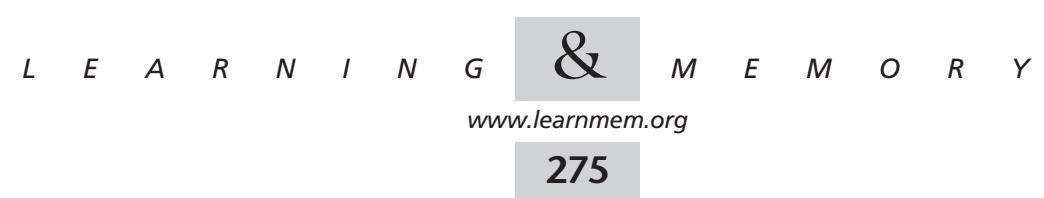




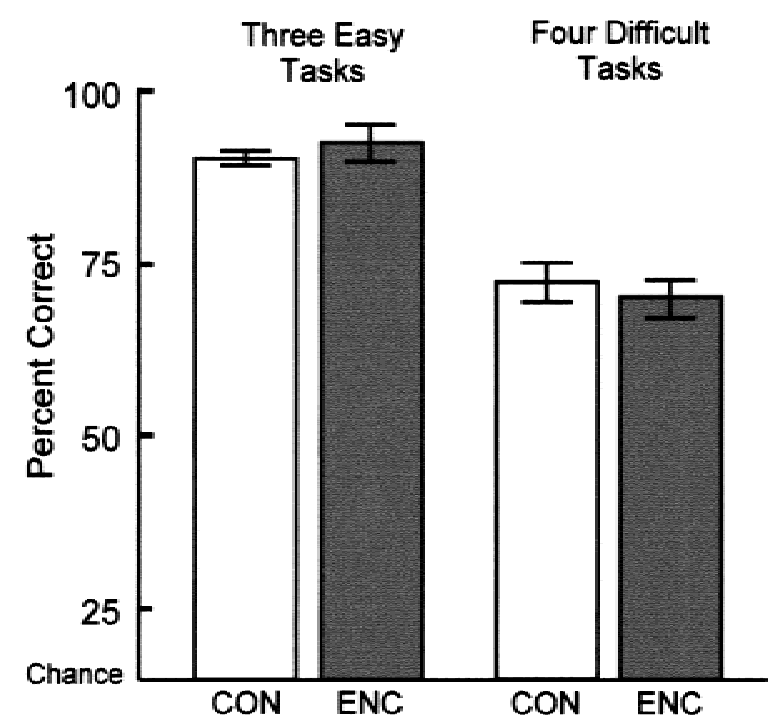

Figure 3 Results from the three easy perceptual tasks (size, color, polygon discrimination) and four more difficult tasks (the face discrimination task and the three visually degraded object-discrimination tasks with a "snow mask" covering 30\%-80\% of each object). Performance on the three easy tasks has been reported to be unimpaired in monkeys with perirhinal damage, and performance on the difficult tasks has been reported to be impaired (Buckley et al. 1998; Buckley and Gaffan, in press). Performance is shown both for five control volunteers (CON) and for three amnesic patients with large medial temporal lobe lesions resulting from herpes simplex encephalitis (ENC). Error bars indicate the standard error of the mean.

lesions have not been published for the monkeys given the tasks used in the present study, the material examined so far has not indicated damage to area TE (M. Buckley, pers. comm.). If damage to area TE can be ruled out, the most likely explanation of the available data may be that the perirhinal cortex in humans is functionally different from the

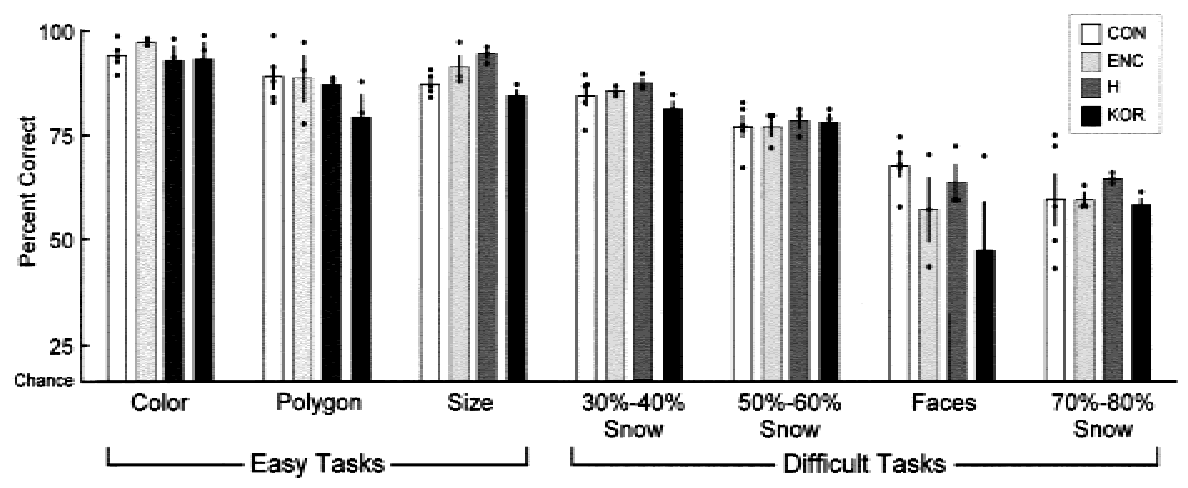

Figure 4 Results from all seven tests for all four groups of participants averaged across the three test sessions (CON, five controls; ENC, three amnesic patients with large medial temporal lobe lesions due to encephalitis; $\mathrm{H}$, three amnesic patients with damage limited to the hippocampal formation; and KOR, three amnesic patients with diencephalic damage due to Korsakoff's syndrome). None of the amnesic groups were impaired relative to controls on any test. Average scores for individual participants are shown (black dots) along with the standard error of the mean for each group (error bars). The tests are ordered according to how difficult they were for the controls (CON). perirhinal cortex in monkeys with respect to visual perception. Neuroimaging evidence provides some support for this view, in that the area of the lateral temporal lobe involved in processing complex visual objects is situated more posteriorly and ventrally in humans than in monkeys (Sergent et al. 1992; Haxby et al. 1994; Ungerleider and Haxby 1994). Perhaps this difference extends to the medially situated perirhinal cortex as well. Further study of monkeys with perirhinal cortex lesions will be important to explore this possibility in more detail.

\section{MATERIALS AND METHODS}

M. Buckley graciously provided the stimuli and tasks so that the same task administered previously to monkeys (Buckley et al. 1998; Buckley and Gaffan, in press) could be administered to our patients. On the basis of pilot studies, tasks that were regularly performed without error were excluded from the study. For each of the remaining seven tasks, six stimuli were presented on a computer screen in two rows of three, and participants decided which one of the six stimuli did not belong with the group.

\section{Participants}

Nine amnesic patients (Table 1) and five healthy control volunteers participated in the study. Two of the patients were female (L.J. and P.N.), and the remaining 12 participants were male. Three of the patients (E.P., G.P., and G.T.) have extensive bilateral damage to the medial temporal lobe due to herpes simplex encephalitis and variable damage to antero-lateral temporal cortex. The lesions for the three patients in the encephalitic group include, bilaterally, the hippocampal region (CA fields, dentate gyrus, and subiculum), the entorhinal cortex, the perirhinal cortex, the parahippocamal cortex, and the amygdaloid complex (see Fig. 2; Schmolck, Stefanacci, and Squire, in press). Three of the patients (A.B., L.J., and P.H.) have damage thought to be limited to the hippocampal region. For L.J. (Reed and Squire 1998) and P.H. (Polich and Squire 1993), hippocampal damage has been confirmed by magnetic resonance imaging (MRI). A.B. became amnesic following an anoxic episode in 1976 and is presumed to have hippocampal damage as a result of this etiology (Cummings et al. 1984; Rempel-Clower et al. 1996). Because A.B. wears a pacemaker, he is ineligible for MRI studies. Finally, three of the patients (M.H., P.N., and J.W.) have Korsakoff"s syndrome. For P.N. and J.W., quantitative radiographic studies demonstrate reduced volume of mammillary nuclei, reduced thalamic density, and frontal lobe atrophy (Shimamura et al. 1988; Squire et al. 1990). The five healthy volunteers were matched to the ENC group with respect to age, education, and gender (mean age $=64.6 \mathrm{yr}$, range $=50-72 \mathrm{yr}$; mean education $=13.4 \mathrm{yr}$, range $=$ 12-16 yr).

\section{Materials}

Seven different tasks were used, all of which had been given previously to

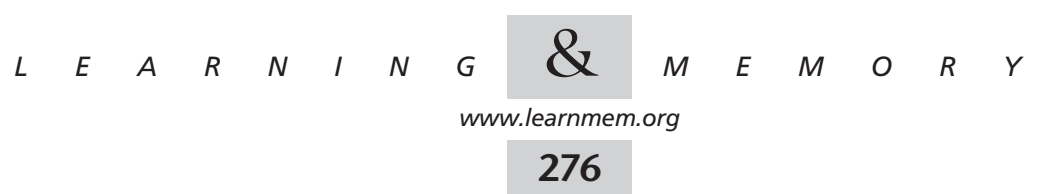


Table 1. Characteristics of amnesic patients

\begin{tabular}{|c|c|c|c|c|c|c|c|c|c|}
\hline \multirow[b]{2}{*}{ Patient } & \multirow{2}{*}{$\begin{array}{l}\text { Lesion } \\
\text { etiology }\end{array}$} & \multirow{2}{*}{$\begin{array}{l}\text { Date of } \\
\text { birth }\end{array}$} & \multirow{2}{*}{$\begin{array}{c}\text { WAIS-R } \\
\text { IQ }\end{array}$} & \multirow{2}{*}{$\begin{array}{l}\text { Years of } \\
\text { education }\end{array}$} & \multicolumn{5}{|c|}{ WMS-R } \\
\hline & & & & & Attention & Verbal & Visual & General & Delay \\
\hline EP & ENC & 1922 & 101 & 12 & 94 & 59 & 92 & 68 & 56 \\
\hline GP & ENC & 1946 & 98 & 16 & 102 & 79 & 62 & 66 & $<50$ \\
\hline GT & ENC & 1936 & 92 & 12 & 120 & 57 & $<50$ & $<50$ & $<50$ \\
\hline$A B$ & $\mathrm{H}$ & 1937 & 104 & 20 & 87 & 62 & 75 & 54 & $<50$ \\
\hline $\mathrm{PH}$ & $\mathrm{H}$ & 1922 & 120 & 19 & 117 & 67 & 83 & 70 & 57 \\
\hline LJ & $\mathrm{H}$ & 1937 & 98 & 12 & 105 & 83 & 60 & 69 & $<50$ \\
\hline $\mathrm{MH}$ & KOR & 1920 & 107 & 10 & 104 & 83 & 83 & 78 & 80 \\
\hline $\mathrm{PN}$ & KOR & 1927 & 99 & 11 & 81 & 77 & 73 & 67 & 53 \\
\hline JW & KOR & 1936 & 98 & 14 & 104 & 65 & 70 & 57 & 57 \\
\hline $\begin{array}{l}\text { Mean } \\
(n=9)\end{array}$ & & & 101.9 & 14 & 101.6 & 70.2 & 70.0 & 64.3 & 55.9 \\
\hline
\end{tabular}

Note. The WAIS-R and the WMS-R indices yield a mean score of 100 in the normal population with a standard deviation of 15 . The WMS-R does not provide scores for individuals who score below 50 . Therefore, the six scores below 50 were scored as 50 for calculating the group mean. WAIS-R, Wechsler Adult Intelligence Scale-Revised (Wechsler 1981); WMS-R, Wechsler Memory Scale-Revised (Wechsler 1987). ENC = patients with amnesia due to encephalitis; $\mathrm{H}=$ patients with damage limited to the hippocampal formation; KOR = patients with Korsakoff's syndrome.

monkeys using the same materials (Buckley 1998; Buckley and Gaffan, in press).

\section{Task 1: Color Discrimination}

A base color $(R=40, G=40, B=0)$ was used to define eight additional isoluminant colors by varying the red and green values. On each trial, six squares (each side $=128$ pixels or $39 \mathrm{~mm}$ ) were presented in either the base color or a randomly selected isoluminant color. Five squares were presented in one color, and the sixth square was presented in the other color. The odd color (presented only once) was randomly determined (16 possible pairings), as was the location of the odd colored square in the $2 \times 3$ display (making a total of 96 possible configurations).

\section{Task 2: Polygon Discrimination}

Polygons had 3-10 sides and were equated for area (12,100 pixels or $1123 \mathrm{~mm}^{2}$ ). On any given trial, five examples of one polygon were presented together with another polygon. One polygon always had two more sides than the other (e.g., a triangle and a pentagon). The odd polygon was randomly determined (12 possible pairings), as was the location of the odd polygon in the $2 \times 3$ display (making a total of 72 possible configurations).

\section{Task 3: Size Discrimination}

Five identical unfilled squares, ranging from 30 to 128 pixels per side $(9-39 \mathrm{~mm})$ were presented together with another square (also 30-128 pixels per side). On any given trial, the length of the sides of the odd square differed randomly from the other five squares by $4,8,16,32$, or 64 pixels $(1.2-19.6 \mathrm{~mm})$ per side. The location of the odd square in the $2 \times 3$ display was randomly determined.

\section{Tasks 4-6: Visually Degraded Object \\ Discrimination ("Snow")}

Three sets of ten three-dimensional objects were used to construct three different tasks. Each object could appear in any of six different orientations. On each trial, five different orientations of one object were presented with the sixth orientation of a different object. The odd object was randomly determined (180 possible pairings), as was the orientation of the odd object and the location of the odd object in the $2 \times 3$ display (making a total of 6480 possible configurations). A white-noise mask was placed over each object such that the probability of obscuring each pixel was $30 \%-$ $40 \%$ (Task 4, Fig. 1a), 50\%-60\% (Task 5), or 70\%-80\% (Task 6 , Fig. 1b).

\section{Task 7: Face Discrimination}

Ten male human faces were used, each photographed in black and white from six different orientations. On each trial, five orientations of one face were shown together with the sixth orientation of a different face (Fig. 1c). The odd face was randomly determined (180 possible pairings), as was the orientation of the odd face and the location of the odd face in the $2 \times 3$ display (making a total of 6480 possible configurations).

\section{Procedure}

Each participant received the same seven tasks in the same order in each of three separate test sessions ("Snow", Face, Color, "Snow", Size, Polygon, and "Snow"). Test sessions were scheduled at least one wk apart. The order in which the three "Snow" tasks was given was counterbalanced across the three test sessions. The assignment of the three object sets to level of "Snow" was also counterbalanced across the three test sessions. In each task, 40 trials were presented on a laptop computer equipped with an active-matrix LCD screen. On each trial, six stimuli were presented in two rows of three, and participants pressed one of six keys to indicate which of the six stimuli was different from the other five. Trials were self-paced.

\section{ACKNOWLEDGMENTS}

We thank Jennifer Frascino, Shauna Stark, and Joyce Zouzounis for their assistance with data collection. We also thank Mark Buckley for providing the stimuli and tasks. This research was supported by the Medical Research Service of the Department of Veterans Affairs, National Institute of Health Grants MH24600 and MH12278, the National Alliance for Research on Schizophrenia and Depression (NARSAD), and the Metropolitan Life Foundation.

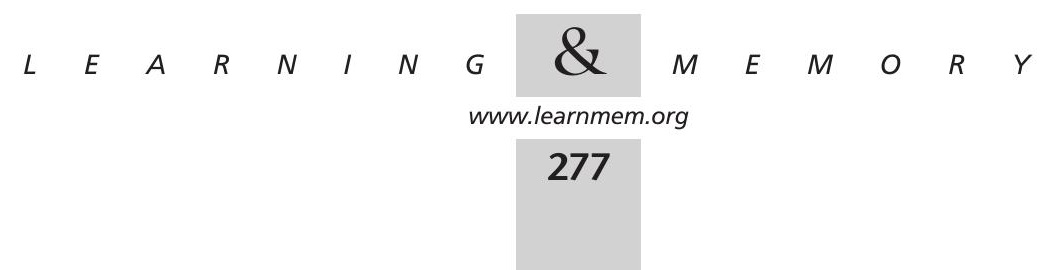


The publication costs of this article were defrayed in part by payment of page charges. This article must therefore be hereby marked "advertisement" in accordance with 18 USC section 1734 solely to indicate this fact.

\section{REFERENCES}

Biber, C., Butters, N., Rosen, J., Gerstman, L., and Mattis, S. 1981. Encoding strategies and recognition of faces by alcoholic Korsakoff and other brain-damaged patients. J. Clin. Neuropsy. 3: 315-330.

Buckley, M.J., Booth, M.C.A., Rolls, E.T., and Gaffan, D. 1998. Selective visual-perceptual deficits following perirhinal cortex ablation in the macaque. Soc. Neurosci. Abstr. 24: 18.

Buckley, M.J. and Gaffan, D. 1997. Impairment of visual object-discrimination learning after perirhinal cortex ablation. Behav. Neurosci. 111: 467-475.

. 1998a. Learning and transfer of object-reward associations and the role of the perirhinal cortex. Behav. Neurosci. 112: 15-23.

. 1998b. Perirhinal cortex ablation impairs visual object identification. J. Neurosci. 18: 2268-2275.

. In press. The hippocampus, perirhinal cortex and memory in the monkey. In Brain, Perception and Memory (ed. J. Bolhuis). chap. 16.

Buffalo, E.A., Ramus, S.J., Clark, R.E., Teng, E., Squire, L.R., and Zola, S.M. 1999. Dissociation between the effects of damage to perirhinal cortex and area TE. Learn. Mem. 6: 572-599.

Buffalo, E.A., Reber, P.J., and Squire, L.R. 1998. The human perirhinal cortex and recognition memory. Hippocampus 8: 330-339.

Cummings, J.L., Tomiysau, S., Read, S., and Benson, D.F. 1984. Amnesia with hippocampal lesions after cardiopulmonary arrest. Neurology 34: 679-681.

Dricker, J., Butters, N., Berman, N., Samuels, I., and Carey, S. 1978. Recognition and encoding of faces by alcoholic Korsakoff and right hemisphere patients. Neuropsychologia 16: 683-395.

Eacott, M.J., Gaffan, D., and Murray, E.A. 1994. Preserved recognition memory for small sets, and impaired stimulus identification for large sets, following rhinal cortex ablations in monkeys. Eur. J. Neurosci. 6: $1466-1478$.

Gross, C.G. 1973. Visual functions of inferotemporal cortex. In Handbook of Sensory Physiology (ed. R. Jung), pp. 451-452. Springer, Berlin.

Haxby, J.V., Horwitz, B., Ungerleider, L.G., Maisog, J.M., Pietrini, P., and Grady, C.L. 1994. The functional organization of human extrastriate cortex: A PET-rCBF study of selective attention to faces and locations. J. Neurosci. 14: 6336-6353.

Milner, B., Squire, L.R., and Kandel, E.R. 1998. Cognitive neuroscience and the study of memory. Neuron 20: 445-468

Mishkin, M. 1982. A memory system in the monkey. Philos. Trans. R. Soc. Lond. B 298: 85-92.

Mishkin, M. and Murray, E.A. 1994. Stimulus recognition. Curr. Opin. Neurobiol. 4: 200-206.

Miyashita, Y. 1993. Inferior temporal cortex: Where perception meets memory. Annu. Rev. Neurosci. 16: 245-264.

Polich, J. and Squire, L.R. 1993. P300 from amnesic patients with bilateral hippocampal lesions. EEG Clin. Neuropsychol. 86: 408-417.

Reed, J.M. and Squire, L.R. 1998. Retrograde amnesia for facts and events: Findings from four new cases. J. Neurosci. 18: 3943-3954.

Rempel-Clower, N., Zola, S.M., Squire, L.R., and Amaral, D.G. 1996. Three cases of enduring memory impairment following bilateral damage limited to the hippocampal formation. J. Neurosci. 18: 3943-3954.

Schmolck, H., Stefanacci, L., and Squire, L.R. Detection and explanation of sentence ambiguity are unaffected by hippocampal lesions but are impaired by larger temporal lobe lesions. Hippocampus (in press).

Sergent, J., Ohta, S., and MacDonald, B. 1992. Functional neuroanatomy of face and object processing. Brain 115: 15-36.

Shimamura, A.P., Jernigan, T.L., and Squire, L.R. 1988. Korsakoff's syndrome: Radiological (CT) findings and neuropsychological correlates. J. Neurosci. 8: 4400-4410.

Squire, L.R., Amaral, D.G., and Press, G.A. 1990. Magnetic resonance imaging of the hippocampal formation and mammillary nuclei distinguish medial temporal lobe and diencephalic amnesia. $J$. Neurosci. 10: 3106-3117.

Squire, L.R. and Zola, S.M. 1997. Amnesia, memory and brain systems Philos. Trans. R. Soc. Lond. B 352: 1663-1673.

Suzuki, W. 1996. The anatomy, physiology and functions of the perirhinal cortex. Curr. Opin. Neurobiol. 6: 179-186.

Suzuki, W.A. and Amaral, D.G. 1994. Perirhinal and parahippocampal cortices of the macaque monkey: Cortical afferents. J. Comp. Neruol. 350: 497-533.

Ungerleider, L.G. and Haxby, J.V. 1994. "What" and "where" in the human brain. Curr. Opin. Neurobiol. 4: 157-165.

Received June 20, 2000; accepted in revised form July 14, 2000. 


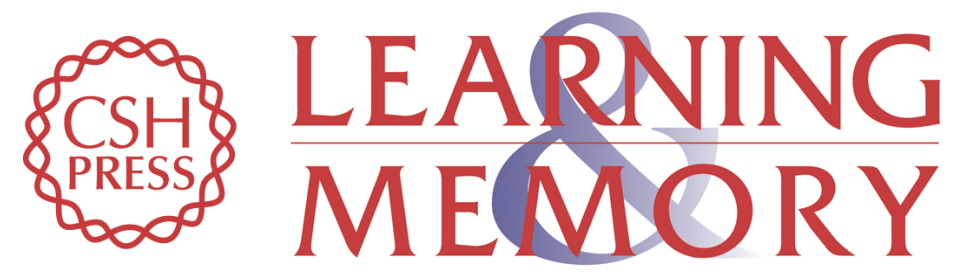

\section{Intact Visual Perceptual Discrimination in Humans in the Absence of Perirhinal Cortex}

Craig E.L. Stark and Larry R. Squire

Learn. Mem. 2000, 7:

Access the most recent version at doi:10.1101/lm.35000

References This article cites 22 articles, 7 of which can be accessed free at: http://learnmem.cshlp.org/content/7/5/273.full.html\#ref-list-1

License

Email Alerting Receive free email alerts when new articles cite this article - sign up in the box at the Service top right corner of the article or click here. 